\title{
"SEGURANDO NA MÃO DE DEUS": ORGANIZAÇÕES RELIGIOSAS E APOIO AO EMPREENDEDORISMO
}

\author{
"HOLDING GOD'S HAND": RELIGIOUS ORGANIZATIONS AND SUPPORT TO \\ ENTREPRENEURIAL INITIATIVES
}

"DE MANOS DADAS CON DIOS": ORGANIZACIONES RELIGIOSAS Y APOYO AL EMPRENDEDORISMO

\section{RESUMO}

Este artigo investiga mecanismos de apoio ao empreendedorismo proporcionados por organizações religiosas. Foram pesquisadas duas organizações, uma católica e outra evangélica, por meio de estudo de caso qualitativo. A análise comparativa baseou-se em três dimensões específicas do apoio ao empreendedorismo que emergiram na própria pesquisa de campo e que denominamos espaços de informação, formação e motivação. Consideramos tais dimensões como importantes achados desta pesquisa e as utilizamos como categorias para investigar o impacto dos mecanismos oferecidos pelas organizações religiosas nas etapas do processo de empreendedorismo. Os resultados do trabalho indicam uma confluência entre os dois casos: o pertencimento às igrejas resulta na formação de capital social orientado para as várias dimensões econômicas e no reforço religioso à motivação econômica. As diferenças, contudo, encontram-se na representação religiosa do significado do sucesso econômico e na articulação e fechamento de suas respectivas redes sociais.

PALAVRAS-CHAVE Empreendedorismo, organizações religiosas, capital social, recursos organizacionais, redes sociais.

Mauricio Custódio Serafim serafim.esag@gmail.com

Professor da Escola Superior de Administração e Gerência, Universidade do Estado de Santa Catarina - Florianópolis - SC, Brasil

Ana Cristina Braga Martes ana.martes@fgv.br

Professora da Escola de Administração de Empresas de São Paulo, Fundação Getulio Vargas - São Paulo - SP, Brasil

Carlos L. Rodriguez rodriguezc@uncw.edu

Professor at Cameron School of Business, University of North Carolina at Wilmington - Wilmington - NC, United States

Abstract The article investigates mechanisms offered by religious organizations to support entrepreneurial initiatives. We examine two organizations, one catholic and one protestant, using a qualitative case study design. The comparative assessment was based on three dimensions of support that appeared as a result of the data analysis, that we called spaces of information, formation, and motivation. The dimensions are considered as possible important research results and were used to investigate the impact on the traditional stages of the entrepreneurial process of the mechanisms made available by the two religious organizations. The analysis indicates certain similarities between the two cases: church membership assists in the creation of social capital that impacts various economic dimensions, as well as provides religious support to the economic motivations. However, the differences between the two churches become evident in the religious interpretation of economic success and in the articulation and closure of their social networks.

keywords Entrepreneurship, religious organizations, social capital, organizational resources, social network.

Resumen Este artículo investiga los mecanismos de apoyo al emprendedorismo proporcionados por organizaciones religiosas. Fueron investigadas dos organizaciones, una católica y otra evangélica, por medio de un estudio de caso cualitativo. El análisis comparativo se basó en tres dimensiones específicas del apoyo al emprendedorismo que emergieron en el mismo estudio de campo y que denominamos espacios de información, formación y motivación. Consideramos tales dimensiones como importantes hallazgos de esta investigación y las utilizamos como categorías para investigar el impacto de los mecanismos ofrecidos por las organizaciones religiosas en las etapas del proceso de emprendedorismo. Los resultados del trabajo indican una confluencia entre los dos casos: la pertenencia a las iglesias resulta en la formación de capital social orientado hacia las varias dimensiones económicas y en el refuerzo religioso a la motivación económica. Las diferencias, no obstante, se encuentran en la representación religiosa del significado del "éxito" económico y en la articulación y "closure" de sus respectivas redes sociales.

Palabras clave Emprendedorismo, organizaciones religiosas, capital social, recursos organizacionales, redes sociales. 


\section{INTRODUÇÃo}

Estudar as ligações entre mentalidade empresarial moderna e religião nos conduz a um tema clássico das Ciências Sociais. Segundo Max Weber, valores conformam ações e afetam processos econômicos: o ascetismo religioso contribuiu para aumentar a racionalidade da conduta humana e, portanto, para a expansão do capitalismo moderno, apoiado, sobretudo, na organização racional de empreendimentos econômicos. No entanto, foi especialmente Emile Durkheim, e não Weber, o autor clássico da sociologia que mais se preocupou em compreender o papel crucial das instituições - inclusive igrejas e comunidades religiosas - para assegurar a coesão social, que se encontrava ameaçada na sociedade industrial do século XIX. Assim, por um lado, podemos afirmar, acompanhando Weber, que valores conformam diferentes tipos de comportamentos econômicos, tais como descritos em seus trabalhos sobre religião e economia (SWEDBERG, 2005). Por outro, seguindo Durkheim (1978), somos levados a considerar que laços sociais e comunitários, assim como outras formas de socialização, configuram um conjunto de atributos sociais que precedem o contrato, isto é, são requisitos de qualquer sistema econômico. As organizações religiosas - duas igrejas, no caso deste trabalho - podem ser consideradas um bom exemplo desse tipo de socialização, por propiciarem relações de solidariedade, confiança e redes de ajuda mútua. Pesquisas recentes vêm demonstrando que tais benefícios têm impactos positivos nas várias fases do processo de empreendedorismo (OZGEN; BARON, 2007; MARTES, 2011).

Com o crescimento do pentecostalismo no Brasil - somos simultaneamente o maior país católico e pentecostal do mundo (BERGUOCI, 2007) - e com a reação da Igreja Católica a esse crescimento (SOUZA, 2005), tal espaço de socialização ganhou novas configurações. Surgiram novos tipos de cultos, cursos, palestras e associações como forma de apoio ao desenvolvimento profissional/empresarial e de reorientação financeira do orçamento familiar, além de projetos que visam atenuar a miséria via envolvimento de empresários-membros. Apesar de alguns estudos mostrarem a importância desse fenômeno (e.g. SIEPIERSKI, 2003; MARTES; RODRIGUEZ, 2004a, 2004b; PINTO; LEITÃO, 2006; MESQUITA, 2007; SERAFIM; ANDION, 2010), a relação entre empreendedorismo e religião não vem recebendo a atenção necessária por parte da academia brasileira, a julgar pela escassez de trabalhos publicados, que pode ser verificada na bibliografia apresentada ao final deste artigo.

Este trabalho procura contribuir para preencher essa lacuna encontrada na bibliografia brasileira sobre o tema, tendo como objetivos: (a) analisar as maneiras pelas quais duas organizações religiosas disponibilizam recursos simbólicos e materiais, de modo a incentivar (no nível discursivo) e apoiar (oferecendo recursos organizacionais) a formação e o crescimento de empresas de propriedade de seus seguidores, e (b) investigar possíveis diferenças nos métodos por elas utilizados. Para tanto, o artigo está estruturado em torno de dois pontos: (1) as igrejas favorecem, enquanto organização, a formação de redes onde prosperam a confiança e o capital social, fundamentais para os negócios; (2) as igrejas incentivam a racionalidade da conduta em relação aos negócios - ou seja, planejamento e maior organização -, disponibilizam recursos materiais e conhecimento da área, assim como propiciam motivação econômica, entendida aqui como crença na capacidade de empreender o próprio negócio. Contudo, se as igrejas oferecem tais recursos, elas não o fazem da mesma maneira, e a diversidade de mecanismos utilizados por cada uma, assim como eventuais diferenças em sua eficácia, apresenta-se como importante questão de pesquisa. Vale ainda mencionar que, não tendo os autores do trabalho encontrado na literatura uma tipologia de mecanismos de apoio à iniciativa de criação de negócios oferecidos por organizações de caráter associativo, especialmente de natureza religiosa, um importante subproduto da pesquisa foi a determinação de três dimensões ligadas ao processo de empreendedorismo em torno das quais os recursos disponibilizados parecem se estruturar.

O trabalho está organizado da seguinte forma: na seção inicial, fazemos uma breve revisão conceitual relacionada ao tema empreendedorismo e sua relação com religião e capital social; os procedimentos metodológicos adotados são descritos a seguir, antecedendo a apresentação dos casos das duas organizações religiosas. A seção seguinte analisa os resultados da pesquisa e compara os procedimentos adotados pelas duas organizações. Na conclusão, apresentamos algumas possíveis contribuições do trabalho e oferecemos sugestões para o prosseguimento dessa linha de investigação. 


\section{AÇÕES EMPREENDEDORAS IMERSAS NAS REDES RELIGIOSAS}

O surgimento das grandes corporações, a expansão do estado de bem-estar social e o crescente aumento da burocratização, processos intensificados após a Segunda Guerra, contribuíram para o declínio das atividades empreendedoras a favor do emprego nas grandes corporações. A função do empreendedor foi sendo substituída pelo quadro técnico das grandes empresas. A intuição, a capacidade de perceber oportunidades, a vontade e a força de levá-las adiante foram repassadas para as equipes de especialistas em planejamento estratégico, e o indivíduo inovador deu lugar ao departamento de pesquisa e desenvolvimento (LÓPEZ-RUIZ, 2004). Solidificou-se a "sociedade de empregados" (MILLS, 1969), cujo ator principal não era mais o empreendedor, mas o que Whyte Jr. (1956) chamou de "homem organização": indivíduos de uma nova classe média que confundiam seus objetivos pessoais com os objetivos da organização em que trabalhavam.

Contudo, a importância do empreendedorismo ressurge nos anos 1980, devido ao processo de reestruturação produtiva, novos padrões de concorrência internacional e precarização do trabalho, assim como às dificuldades surgidas na estrutura funcional do setor público. Dentro desse novo contexto, o próprio conceito de empreendedorismo foi revisto e alguns autores passaram a associá-lo com a criação de novas organizações (THORNTON, 1999; ALDRICH, 2005). Essa é, também, a definição adotada neste artigo. Especificamos, contudo, que, para fins de operacionalização da pesquisa, concebemos empreendedorismo como abertura e/ou desenvolvimento de um negócio próprio ou autoemprego. As etapas desse processo, que descreveremos com mais detalhes na seção a seguir, incluem iniciativas sequenciais de: (a) reconhecimento ou identificação da oportunidade: (b) avaliação da oportunidade; (c) exploração da oportunidade (BYGRAVE; HOFER, 1991; SHANE; VENKATARAMAN, 2000). Mais recentemente, as pesquisas sobre empreendedorismo têm se beneficiado da abordagem da sociologia econômica. Tal abordagem enfatiza a cultura (DIMAGGIO, 2003), as práticas sociais e a imersão social (GRANOVETTER, 1985) para analisar ação e processos econômicos.

$\mathrm{Na}$ perspectiva da sociologia econômica, a religião é considerada não como um conjunto de ideias concernentes à transcendência, mas como prática social. Dito de outro modo, estudar a religião significa adentrar um intrincado conjunto de práticas, inclusive cotidianas, relacionadas às esferas do trabalho, consumo e negócios. O comportamento econômico, socialmente imerso, está também imerso nas práticas e relações sociais e religiosas (WUTHNOW, 1994, 2005). Nessa perspectiva, pode-se considerar que a ação empreendedora é incentivada, por um lado, pelas relações interpessoais, capazes de propiciar recursos econômicos, relacionais e informacionais (MARTES; RODRIGUEZ, 2004a; 2004b), e, por outro, por aspectos socioculturais, como a aprovação do grupo a determinadas atividades econômicas e a aceitação de valores e princípios comunitários (DIMAGGIO, 2003). Assim, a abordagem da sociologia econômica permite compreender a atividade empreendedora por meio da: (a) estrutura social propiciada pela igreja enquanto organização; (b) cultura religiosa, que pode ser entendida como orientação doutrinária/ teológica capaz de atribuir sentido e motivar a ação empreendedora.

Adicionalmente, a igreja gera e propicia internamente, a seus membros, recursos organizacionais que são fatores-chave para a abertura de negócios. Isso é especialmente importante para aqueles que possuem níveis insuficientes de capital físico e capital humano. Entretanto, talvez o principal tipo de capital gerado pela associação de um indivíduo a uma organização religiosa seja o capital social.

Há pelo menos duas abordagens sobre capital social. A primeira está relacionada com os trabalhos de Coleman $(1988,1990)$ e Putnam $(1993,2000)$ e refere-se à facilitação da ação por meio das estruturas sociais. Enquanto para Coleman capital social é definido pela sua função e é "[...] uma variedade de entidades diferentes, com dois elementos em comum: consistem de algum aspecto das estruturas sociais e facilitam certas ações dos atores - sejam pessoas ou atores corporativos - no interior da estrutura" (COLEMAN, 1988, p. S98), o ponto central para Putnam são as várias formas de interação entre os indivíduos, que resultam em uma ação coletiva que contribui para o civismo ou a vida humana associada em forma de comunidade. Quanto maior a rede de engajamento cívico - seja nas associações de moradores, grupos religiosos, festas de bairro etc. - e maiores as conexões entre os indivíduos, maior o capital social.

A segunda abordagem está relacionada com autores como Bourdieu (1986), Burt (1997, 2000, 2001, 2004) e Lin (1999, 2006), que enfatizam os recursos - como informações e apoios - que os indivíduos ou grupos 
conseguem ter acesso devido às suas relações sociais. Nesse sentido, os mecanismos de rede no qual está imerso o indivíduo - que pode ser caracterizada por quem interage com quem, com qual frequência e de que maneira - influenciam o fluxo de recursos através dessa rede. Aqueles indivíduos com melhores posições na rede - o que significa acesso a mais e melhores recursos - possuem maior capital social do que outros que estão em uma posição relativamente pior.

Para essa segunda abordagem, uma contribuição digna de nota é a de Burt (1997, 2000, 2001, 2004). Ao tratar da vantagem competitiva proporcionada pela estrutura das redes do indivíduo e pela localização de seus contatos nessa rede, o autor define capital social como "relacionamentos com outros players", isto é, "amigos, colegas e contatos de uma maneira geral por meio dos quais você recebe oportunidades para usar seu capital financeiro e humano" (BURT, 2004, p. 326). Para o autor, capital social são, ao mesmo tempo, os meios de contatos mantidos (ou quem se alcança) e a estrutura desses contatos na rede (ou como se alcança) e que dependendo da configuração - proporcionam maior ou menor participação na e controle da informação (BURT, 2000, 2001). Burt se concentra no como e desenvolve a ideia de buraco estrutural, definido como uma "separação entre contatos não redundantes" (BURT, 2004, p. 334). Enquanto para Coleman e Putnam as redes densas são condições necessárias para o surgimento do capital social, na visão de Burt, é a relativa ausência de laços - ou buracos estruturais - que o proporciona. Essa abordagem salienta que as redes densas tendem a produzir informações redundantes, enquanto os laços fracos (GRANOVETTER, 1973) - correlacionados com o buraco estrutural - podem ser fontes de novas informações, recursos e oportunidades.

Apesar das diferentes abordagens do conceito, Portes (1998, p. 6) afirma que é possível se detectar um consenso crescente na literatura de que capital social pode ser considerado como "a habilidade de atores para obter benefícios por estarem na qualidade de membros de uma rede social ou de outras estruturas sociais". O conceito descreve os benefícios que o agente econômico pode obter (conhecimento, informação, poder, influência e apoio) por participar de uma rede social. Para os nossos propósitos, entendemos redes sociais como um conjunto de atores (pessoas ou organizações) conectados por relações sociais ou laços de um tipo específico (CASTILLA et al., 2000). As redes podem incluir tanto relações formalmente instituídas quanto relações informais e são simultaneamente resultado e causa de um conjunto de forças que agem sobre as pessoas ou unidades sociais (KOENIG; GOGEL, 1981, p. 40).

Adotando o ponto de vista de Coleman e Putnam, capital social cresce com a inserção dos indivíduos nas redes sociais, na medida em que propicia a elevação do número de contatos com novos indivíduos e novas redes, solidifica valores que agilizam e facilitam as decisões e favorece a emergência de redes de ajuda mútua. Confiança, solidariedade e uma série de valores éticos e comunitários reforçam laços de pertencimento e ajudam a construir e adensar relações sociais que facilitam a ação, inclusive a econômica. Portanto, "pertencer a um grupo é possuir um capital, ou seja, é possuir um recurso que facilita as ações entre os agentes, tornando desnecessárias todas as precauções a serem tomadas nos casos em que a honestidade e a confiança estão ausentes" (STEINER, 2006, p. 81).

Indo mais ao ponto, há duas propriedades específicas das estruturas sociais que facilitam a criação de capital social, que Coleman (1988) denomina "fechamento [closure, no original] de redes sociais" e "organização social apropriável (appropriable)". A primeira refere-se à existência de laços sociais em número suficiente para garantir que, em uma determinada rede, as normas sejam estritamente observadas, inclusive por meio de sanções. Como um dos resultados, tais normas passam a ser apropriadas e a orientar a comunidade, de modo a facilitar, inclusive, transações econômicas sem o recurso de contratos legais. Tal fechamento aumenta a confiabilidade, pois a renúncia de uma obrigação ou promessa torna-se mais difícil, devido à sanção exercida pelo grupo, colocando em jogo a reputação dos atores que descumprem com sua expectativa. Dessa forma, pode-se afirmar que o fechamento favorece a lealdade e a solidariedade em uma dada estrutura social. Porém, o fechamento desfavorece o fluxo de informações relevantes para os atores, por criar redundâncias (GRANOVETTER, 1973). A organização social apropriável, por sua vez, diz respeito a qualquer organização que foi criada para um objetivo e que foi apropriada parcial ou totalmente para outras finalidades. Dessa forma, coloca à disposição seus recursos organizacionais no auxílio a propósitos que não faziam parte de seus objetivos originais, facilitando, dessa forma, as ações de seus membros de tal modo que, sem essa apropriação, não seria possível. Devido a isso, constitui-se em importante fonte de capital social.

Como qualquer outro tipo de capital, o capital social também é produtivo. Segundo Coleman (1988, p. 97), "ele é produtivo porque possibilita a aquisição de 
certos fins que na sua ausência não poderiam ser alcançados. Como capital físico e humano, o capital social não é completamente tangível, mas pode ser específico a certas atividades". Pesquisas sobre capital social vêm mostrando que a religião é um fator importante na formação de redes sociais e confiança (e.g. IANNACCONE; KLICK, 2003; PUTNAM, 2000) e vêm reforçando a ideia de que um nível adequado de capital social entre os membros de uma organização serve para lubrificar as relações entre indivíduos, no sentido de diminuir os custos de transação e facilitar os negócios (MARTES; RODRIGUEZ, 2004a; 2004b).

No caso aqui apresentado, estamos interessados em compreender de que modo o capital social propiciado pelo pertencimento às igrejas é capaz de fomentar o empreendedorismo, ao lado dos recursos materiais e simbólicos que as organizações religiosas disponibilizam a seus membros nas diversas fases do processo de empreendedorismo. Para tanto, realizamos uma pesquisa qualitativa com duas igrejas, cujos procedimentos descrevemos a seguir.

\section{PROCEDIMENTOS METODOLÓGICOS}

Adotamos neste estudo a abordagem intitulada nova sociologia econômica, por permitir compreender o papel das relações interpessoais nos mais variados domínios da vida econômica ou, nas palavras de Granovetter (1985), a imersão da economia na vida social. Nossa intenção é mostrar que as redes religiosas são levadas em conta nas decisões do empreendedor e que diferentes estruturas de suporte proporcionadas pelas instituições religiosas podem levar a resultados também diferentes na concepção e condução dos negócios.

Apresentamos neste trabalho dois estudos de caso qualitativos em perspectiva comparada: 1) Igreja Evangélica Renascer em Cristo (IRC); 2) Movimento dos Focolares (MF), esse último filiado à Igreja Católica, ambos com suas sedes em São Paulo, Brasil. A escolha das duas instituições justifica-se por serem atuantes há mais de 15 anos, contemplarem o segmento de empreendedores de classe média, difundirem um discurso com alvo nesse segmento e disponibilizarem recursos organizacionais específicos para ele. No âmbito do MF, dedicou-se especial atenção ao Polo Spartaco, por tratar-se de um conjunto de empresas ligadas à Igreja Católica. Esta, como se sabe, possui 125 milhões de adeptos no Brasil (dados do Censo 2000 do IBGE) e, de um modo geral, não é reconhecida na literatura como uma instituição cuja doutrina incorpora incentivos ao empreendedorismo. A IRC, por sua vez, foi selecionada por servir como um contraponto à primeira: é uma igreja recente, possui apenas 120 mil fiéis e um discurso claramente direcionado à promoção do sucesso empresarial.

Para a coleta de dados, utilizamos três técnicas. A primeira, observação não participante, foi realizada em 2006 e 2007 e consistiu de 10 visitas às organizações religiosas (Mariápolis Ginetta, sede do MF, e dois templos da IRC), participação em cultos (um na igreja de Alphaville e cinco na Sede Internacional), missas (10 na igreja da Mariápolis Ginetta), um seminário/curso da Arepe sobre planos de negócios, três encontros de empresários e entrevistas informais com seus participantes. Todas as observações foram registradas em caderno de campo.

Entrevista em profundidade foi a segunda técnica utilizada. No MF, foram realizadas oito entrevistas, sendo duas com religiosos, uma com leiga católica, quatro com empresários-membros e uma entrevista com um pesquisador e ex-membro do MF. Na IRC, foram realizadas nove entrevistas: três com bispos envolvidos com a Arepe e seis com empresários-membros da igreja. A seleção dos entrevistados foi feita por meio da técnica bola de neve, segundo a qual os primeiros informantes - selecionados por seu envolvimento em projetos de apoio ao empreendedorismo - recomendam outros para entrevista.

A terceira técnica empregada, análise documental, foi realizada com base em artigos e reportagens de jornais e revistas, folders, sites, material publicitário, memorandos internos das empresas e associações, fotos e regimentos. Foram consultados os jornais Folha de S.Paulo, O Estado de S. Paulo, O Globo, as revistas Veja e Istoé, e sites de notícias evangélicas (como o Gospel+), nesses casos utilizando-se a tecnologia RSS, para se obterem informações sobre as organizações e compará-las com os dados primários coletados. Outro recurso tecnológico foi o site YouTube, onde se encontram vídeos das celebrações religiosas, principalmente da IRC. Selecionamos 20 vídeos que estão disponíveis no endereço http://tinyurl.com/394zml.

A análise de discurso foi utilizada com a finalidade de interpretarmos as entrevistas em profundidade. Tal interpretação foi realizada de modo a garantir que as falas dos entrevistados fossem consideradas com base em seu contexto social. Dessa análise, observamos semelhanças entre as informações que puderam ser 
agrupadas por meio de um processo de categorização simples. A análise do conjunto das entrevistas - também confirmada pelo restante do material empírico - indicou que havia três categorias-chave capazes de classificar e sintetizar as ações de apoio e promoção do empreendedorismo relatadas pelos nossos entrevistados. A essas três categorias chamaremos de dimensões da ação empreendedora. Dito de outro modo, tais dimensões emergiram como achados da própria pesquisa de campo, isto é, da análise do material empírico coletado, e puderam contemplar o escopo geral das atividades promovidas pelas organizações religiosas, embora, evidentemente, sem desconsiderar as particularidades de cada uma delas.

Para a seleção dessas dimensões, inicialmente procuramos pesquisas empíricas como as de Hung e Hsiao (2004), que classificam a mobilização de capital social para apoio ao empreendedorismo também em três dimensões: oportunidade, motivação e habilidade. Entretanto, durante o processo de análise das informações obtidas nas fontes acima mencionadas, percebemos indutivamente que a gama de recursos oferecidos pelas duas organizações religiosas estava estruturada de modo diferente, ou seja, em torno de três dimensões que representavam etapas sequenciais, claramente ligadas ao próprio processo de empreendedorismo, que podiam ser mais apropriadamente descritas como espaços de motivação (tal como em Hung e Hsiao), mas também informação e formação. Isso porque a aquisição e difusão de informação por meio da rede religiosa, a formação proveniente dessa mesma rede (ou seja, investimento no capital humano à luz doutrinal das igrejas), bem como a motivação - apoio emocional/espiritual/profissional baseado nas relações de confiança e solidariedade -, foram as dimensões que mais se destacaram nas entrevistas, observações e análise documental e, por isso, as consideramos como as categorias que melhor agruparam os dados.

Tais dimensões serão apresentadas neste artigo de maneira contextualizada, estabelecendo-se suas conexões com as fases do processo de empreendedorismo, descritas e analisadas mais adiante.

\section{APRESENTAÇÃO DOS CASOS}

\section{Igreja Evangélica}

A Igreja Evangélica Apostólica Renascer em Cristo (IRC) foi fundada em 1986, na cidade de São Paulo, por Estevam Hernandes, ex-gerente de marketing da Xerox e Itautec. Insere-se na linha neopentecostal, que, no plano teológico, se caracteriza pela ênfase na guerra espiritual (ou seja, o embate entre o bem e o mal), na teologia da prosperidade, e rejeita usos e costumes de santidade pentecostal e outros tradicionais símbolos de conversão. Outras características são a adoção de gestão organizacional do tipo empresarial, o uso intensivo dos meios de comunicação - principalmente os eletrônicos - e a ênfase na arrecadação de dinheiro dos fiéis por meio de dízimos, ofertas nos cultos e doações (SIEPIERSKI, 2003).

Desde o início de suas atividades, o bispo Estevam Hernandes e sua esposa, a bispa Sônia Hernandes, escolheram os jovens como público-alvo, atraindo-os com as bandas gospel. Com o tempo, o perfil dos fiéis modificou-se e atualmente há um importante segmento de empresários e profissionais autônomos que frequentam a igreja. A IRC passou a valorizar mais a adesão empresarial do que a dos jovens (SIEPIERSKI, 2003). Pensando no segmento dos empresários, em 1996, foi fundada a Associação Renascer de Empresários e Profissionais Evangélicos (Arepe), que visa apoiar profissionais autônomos, pequenos e médios empresários e iniciantes de negócio próprio. As demais linhas de atuação concentram-se na Fundação Renascer, que, além de administrar projetos assistenciais e de residência para idosos e crianças abandonadas e centros de recuperação para dependentes químicos, funciona como uma espécie de bolding que controla a igreja e as várias organizações a ela ligadas. A IRC estrutura-se também em forma de ministérios, que são áreas de atuação da igreja (e.g., busca de recursos para as obras assistenciais da igreja, grupo de apoio ao usuário de drogas e seus familiares, visitas a doentes e encarcerados) e que têm como função - segundo um dos entrevistados - "atender a todas as necessidades do homem".

A Arepe, por sua vez, tem o objetivo, segundo os entrevistados, de integrar a visão espiritual ao âmbito do trabalho e proporcionar o desenvolvimento profissional de seus membros, com base na doutrina da igreja. Dessa forma, esse ministério oferece diretamente recursos organizacionais e apoio às atividades empreendedoras. A fonte desses recursos é proveniente da própria igreja, que, por sua vez, é financiada pelos fiéis por meio de dízimos, de ofertas nos cultos, do projeto Gideão da Conquista (carnês de pagamento de mensalidades para o financiamento de seus projetos assistenciais e de expansão de suas redes de rádio e TV) e outras doações diversas. A Arepe não possui um 
fundo financeiro próprio e, quando há a necessidade de organizar e executar algum projeto - como palestras e cursos (que serão abordados a seguir) -, cria ações de arrecadação ad hoc, recebendo doações dos empresários. Adicionalmente, para a cobertura de custos, cobra pequenas taxas em alguns desses eventos. Seus membros são voluntários da igreja e não há funcionários que se dediquem exclusivamente a ela.

\section{Igreja Católica}

O MF foi iniciado por Chiara Lubich (1920-2008) em 1943, na Itália, e tem caráter eclesial e civil. Tendo chegado ao Brasil em 1959, está presente atualmente em 182 países, com a participação de 140 mil membros internos e em torno de 2,1 milhões de aderentes e simpatizantes. Segundo um dos entrevistados, a sua característica principal é a espiritualidade da unidade, e o compromisso estabelecido entre seus membros é "viver o mandamento do amor recíproco". Esses dois elementos constituem o que chamam de "paradigma da unidade", que significa a vivência do amor recíproco com vistas à construção da unidade (com pessoas, povos, outras denominações religiosas e na própria Igreja Católica), a fim de "contribuir para a fraternidade universal".

O MF possui a seguinte estrutura organizacional: há uma presidente que dirige o movimento, auxiliada por uma copresidente e um conselho. Sob sua direção estão os "Focolares", pequenas comunidades formadas de homens ou mulheres (separadamente), em torno de quatro a cinco membros denominados focolarinos e focolarinas e que moram, geralmente, em uma casa que serve como local de encontro para seus participantes. Há também os focolarinos casados, que moram com suas famílias. Os "Centros-Zona" são formados por "Focolares" que possuem papel de coordenação e administração do Movimento. As "Mariápolis Permanentes" são pequenas comunidades onde famílias, jovens, padres e religiosos moram e trabalham de maneira comunitária, constituindo-se também como centros de formação social e religiosa do MF. Finalmente, os Centros Mariápolis são locais de encontro (como conferências, congressos, palestras) para os membros e simpatizantes do MF.

Uma das atividades do MF no campo econômico é denominada economia de comunhão (EdC). Proposta por Chiara Lubich, a EdC teve início no Brasil em 1991 e tem como objetivo principal a "transformação cultural da vida econômica e empresarial", tendo como proposta doutrinária o "paradigma da unidade", acima mencionado. Um dos desdobramentos práticos do projeto é disponibilizar parte dos lucros das empresas aos mais pobres, suprindo necessidades básicas e/ou oferecendo postos de trabalho para esses grupos. De um modo mais específico, a proposta contempla a divisão do lucro em três partes: uma voltada para a própria empresa; outra para a difusão da chamada "cultura da partilha”, por meio da organização de congressos, estruturas, bolsas de estudo e divulgação na imprensa; e a terceira parte para os pobres, inicialmente no âmbito dos "Focolares" (PINHEIRO, 2000; BRUNI, 2005). O lucro é considerado um componente estratégico, dado que mediará e processará a partilha. Sob o ponto de vista do desenvolvimento da EdC, as empresas envolvidas são, em sua maioria, de pequeno porte e com faturamento, em geral, não superior a um milhão de dólares/ano. Desde o início da EdC, em 1991, calcula-se que, do universo total de empresas que iniciaram atividades sob sua orientação e apoio, 14\% encerraram suas atividades. No Brasil, atualmente contabilizam-se 123 empresas atuantes, e no mundo há cerca de 700 empresas associadas ao movimento.

A atividade mais importante da EdC direcionada aos empresários é o Polo Empresarial Spartaco, criado em 1994. O polo está localizado no município de Cotia (SP) e abriga seis empresas num regime de condomínio, administrado pela holding Empreendimentos, Serviços e Projetos Industriais S.A. (Espri). A Espri canaliza recursos para as empresas sob a forma de participações feitas por intermédio de subscrição de cotas de capital, cuja propriedade é conservada pelos participantes (atualmente cerca de 3.600 acionistas). As participações no capital são bastante pulverizadas e não há a presença de um acionista ou grupo majoritário. As empresas que atuam no Polo Spartaco pertencem a diversas áreas da indústria (por exemplo, nutrição clínica, embalagens, produtos de limpeza) e do setor de serviços (por exemplo, comércio, educação, serviços médicos e diagnósticos) e, seguindo a filosofia da EdC, enviam parte de seus lucros para a organização.

\section{DISCUSSÃO E ANÁLISE DOS RESULTADOS}

Nesta seção, analisaremos como os recursos criados e disponibilizados pelas organizações religiosas promovem o empreendedorismo entre seus membros e, mais especificamente, como o capital social estimula 
o empreendedorismo. Conforme descrito nos Procedimentos Metodológicos, em decorrência da análise das várias fontes de dados, emergiram três dimensões fundamentais associadas aos recursos organizacionais, quais sejam espaços de informação, espaços de formação e espaços de motivação, que serão abordados a seguir.

Propomos que as três dimensões representam, em realidade, uma tipologia das categorias de mecanismos de suporte às iniciativas empreendedoras, visto que cobrem a gama completa de serviços de apoio que as organizações podem proporcionar a seus membros, referentes às três etapas tradicionais do processo de empreendedorismo (SHANE; VENKATARAMAN, 2000), conforme descreveremos a seguir. Os espaços de informação são peças-chave na fase de identificação de oportunidades de negócio, processo eminentemente cognitivo, no qual o potencial empreendedor tem que estar alerta para as pistas proporcionadas pelo meio ambiente. Alguns autores (e.g., WEBB et al., 2010) destacam o fato de esaa etapa ser bastante facilitada pela interação social, recurso proporcionado em abundância pelas organizações objeto do estudo. Os espaços de formação fornecem conhecimento crítico para a etapa de avaliação de oportunidades, na qual se desenvolve processo racional de exame da atratividade e factibilidade das oportunidades identificadas. O conhecimento e os instrumentos de análise possuídos pelo potencial empreendedor são refinados e utilizados num processo de exame e exclusão, no qual a avaliação de ideias pode ficar ainda mais enriquecida quando efetuada em fóruns formais ou informais de discussão (FELIN; ZENGER, 2009), tais como os oferecidos pelas igrejas aqui estudadas. Finalmente, os espaços de motivação são campo propício para o início das atividades de exploração das oportunidades, etapa que exige, acima de tudo, esforços na mobilização de recursos para implementação (SIRMON; HITT, IRELAND, 2007). Como veremos em seguida, ambas as organizações estudadas procuram disponibilizar para seus membros o acesso a variadas fontes de insumos físicos, financeiros e de conhecimento, proporcionando ainda público-alvo para as iniciativas dos empreendedores, que pesquisas anteriores demonstraram ter características de mercados cativos (e.g., LIGHT, 1972; MARTES; RODRIGUEZ, 2004a; 2004b).

\section{Recursos na IRC}

Os espaços de informação são recursos direcionados para seus membros, mas cujo acesso é independen- te do vínculo com a igreja. Um deles é o site arepe. com.br, administrado por uma das regionais da IRC e cujos serviços são gratuitos ao usuário. Uma de suas funções é a de informar os leitores sobre eventos concernentes às atividades da Arepe. O site também oferece serviços de cadastramento de empresas e de ofertas de emprego. Na página inicial, informa-se que o uso do sistema não é exclusivo para evangélicos e que o único pré-requisito para o usuário é de que "tenha um sonho e um desejo de crescer profissionalmente". Isso remete à possibilidade de que a rede criada por meio do site se conecte com outras redes além do âmbito da igreja e do grupo de evangélicos. Uma terceira função do site é a de oferecer serviços gratuitos de (a) aconselhamento acerca dos negócios ou vida profissional e (b) visitas (para dar bênçãos) e/ou cultos nas empresas. Também há um quiosque, durante os cultos da Arepe, com voluntários da igreja para dar informações e coletar os dados dos interessados, para que algum pastor ou bispo da igreja entre em contato com aqueles que desejam ingressar nesse ministério. Para finalizar, a partir do mês de março de 2007, passou a ser transmitido aos domingos à noite, pela Rede Gospel de TV, o programa Ideias e Negócios, cujo público-alvo são empresários, executivos, profissionais autônomos e os que desejam montar o próprio negócio.

Os espaços de formação definem os contornos do discurso religioso e profissional. Em relação a esse último, são oferecidas - como mencionado anteriormente - palestras, seminários e cursos organizados pela Arepe com o intuito de proporcionar desenvolvimento profissional e incentivo aos empreendedores para se conhecerem e trocarem informações. Os temas abordados abrangem desde as especificidades do mundo dos negócios - tais como finanças, estratégia e vendas - a temas de cunho religioso que tangenciam a gestão, como "o mundo espiritual no mundo dos negócios" (palestra do dia 7 de maio de 2007). As palestras e seminários são proferidos por profissionais de algum destaque no mercado de consultoria ou executivos experientes que geralmente estão ligados à IRC. Esse trabalho é feito voluntariamente, e o acesso é gratuito. Um ponto significativo desses espaços de formação é o incentivo ao relacionamento entre os frequentadores.

A dimensão do discurso é o espaço da legitimação, divulgação e reafirmação dos valores que dão sentido à ação. Resumidamente, o discurso dos membros da IRC baseia-se na existência de um mundo espiritual 
que interfere diretamente no mundo terreno. O mundo espiritual é constituído - além de Deus - de entidades demoníacas que agem no mundo material com o objetivo de reter a prosperidade do homem. A igreja, segundo um pastor, possui a função de proteção contra essas forças e, além de ensinar a guerrear espiritualmente, constitui-se no canal para que a benção de Deus aja sobre as pessoas, liberando a prosperidade. $\mathrm{O}$ instrumento utilizado para colocar em funcionamento a dinâmica da benção é a oferta, que, além do significado material de financiamento da igreja, possui a função espiritual de estabelecer uma espécie de contrato com Deus.

O desdobramento desse discurso no campo profissional é a crença de que ser bem-sucedido nos negócios requer a benção de Deus, além da necessária competência profissional. Para esse tipo de empreendedor, há um termo específico na igreja: empresário apostólico. Esse é o empresário que tem uma conduta pautada na doutrina da igreja e que possui os seguintes objetivos: suprir sua família (porque acreditam que a principal prioridade é a família) e a igreja (por meio do dízimo), ser empreendedor (os entrevistados definiram como aquele que "faz tudo para ser bem-sucedido", de acordo com a doutrina), e conquistar bens materiais (o ter é uma consequência de ser - servo, ter benção, limpo nas intenções).

Os espaços de motivação são os locais onde ocorrem práticas e rituais terapêuticos, que possuem o objetivo de fortalecer os laços de pertencimento e de evitar ou dirimir dúvidas quanto à convicção acerca do discurso da igreja. Um desses espaços é o Culto da Arepe, que acontece às segundas-feiras à noite, em todas as igrejas Renascer. Os pastores ou bispos procuram adaptar as ministrações de modo a oferecer algumas orientações religiosas voltadas à prática dos negócios. Também são lidos o que denominam "testemunhos de vida" de empreendedores, que são experiências bem-sucedidas de acontecimentos específicos e que acreditam ter ocorrido por meio de milagres. Além dos cultos, alguns pastores e bispos que estão envolvidos com esse ministério disponibilizam-se para conversas privadas, atuando como conselheiros nos mais diversos assuntos relacionados aos negócios, vida profissional e pessoal, com o objetivo de oferecer orações e discernimento ao empreendedor em decisões que devem ser tomadas. Adicionalmente, o empreendedor poderá solicitar (via pastor, bispo, site Arepe ou outro membro) visitas a sua empresa de membros do ministério para a realização de cultos, orações e unção das portas da empresa. Nesse caso, um empresário (sozinho ou com um pequeno grupo de voluntários) poderá realizar tais atividades para outro empresário.

\section{Recursos no MF}

Em relação aos espaços de informação do MF e que se referem à EdC, há o site oficial internacional do MF (focolare.org), o site internacional dedicado exclusivamente à EdC (edc-online.org) e o site internacional de rede de empresas vinculadas às EdC (edc-info.org), que se dedica a criar oportunidades de negócios via $\mathrm{B} 2 \mathrm{~B}$, todos traduzidos em cinco línguas. Outro espaço importante de informação - e que é simultaneamente espaço de formação - é o congresso anual da EdC, que acontece desde 1993 na Mariápolis Permanente Ginetta (em Vargem Grande Paulista - SP). Com duração de três dias, reúne pessoas de todo o Brasil e de alguns países da América do Sul, e são realizadas palestras, depoimentos e o Expo EdC, uma exposição de empresas de EdC e de seus produtos. Um terceiro espaço de informação é a rede dos próprios "Focolares", que centralizam informações sobre os acontecimentos da EdC local e nacional e disponibilizam, para os membros do movimento, vídeos com informações atuais do MF no mundo, vídeos de meditação com Chiara Lubich, livros (geralmente da editora Cidade Nova, que pertence ao MF e publica as obras sobre a EdC escritas por membros) e informações detalhadas sobre os eventos. O quarto espaço de informação é o Escritório da EdC, localizado na Mariápolis Ginetta, que tem como função cadastrar as empresas de EdC, seus lucros e doações, coletar informações sobre as pessoas ajudadas e de empresas que poderiam empregá-las e oferecer orientações para os empreendedores que estão iniciando seus negócios e para os que precisam tomar decisões importantes ou enfrentam dificuldades. As Comissões Regionais, que são coordenadoras das atividades da EdC em uma região geográfica, também acompanham as atividades de professores e estudantes interessados na dimensão acadêmica da EdC, mantêm contatos internacionais que propiciam importação/exportação de produtos locais e divulgam soluções desenvolvidas por uma empresa para as demais. As Comissões são formadas por membros do MF e voluntários e estão subordinadas institucionalmente aos Centro-Zonas da respectiva região (veja a seção Apresentação dos casos).

Em relação aos espaços de formação, além do 
congresso mencionado, há as Escolas de EdC, organizadas pelas Comissões Regionais e realizadas uma vez por mês. As Escolas têm o objetivo de formação dos empresários na denominada "cultura da partilha", que no âmbito econômico se traduz em EdC, e seus empreendedores caracterizam-se, segundo o MF, por "uso responsável da própria riqueza", por um "estilo de consumo sóbrio", assim como pela partilha dos próprios recursos com o próximo que se encontra necessitado. No âmbito das organizações econômicas, essa cultura é manifestada na busca pela conciliação da eficiência e rentabilidade empresarial com a dignidade humana, no empenho pela melhoria do ambiente social no qual estão inseridas e na ênfase ao estabelecimento de relacionamentos baseados no amor recíproco com todos os seus stakeholders. Os membros acreditam que o ter (posse de bens) não constitui uma verdadeira riqueza, mas simplesmente a possibilidade efetiva de usufruto e de uso dos bens para atender às próprias necessidades e crescimento, sendo que essas necessidades se medem e esse crescimento acontece em conexão com as outras pessoas. Devido a isso, o ter adquire o significado de partilhar (QUARTANA, 1992).

Em relação aos espaços de motivação, é comum a frequência regular às missas. Outro espaço é a rede dos "Focolares", onde os empreendedores podem conversar sobre vários assuntos (cotidiano, problemas pessoais, familiares, profissionais, entre outros) de modo privado ou com o grupo de focolarinos. As Comissões Regionais possuem também um papel não apenas técnico de dar assistência ao empreendedor, proporcionando igualmente apoio emocional e espiritual quando necessário. Em comunidades organizadas, há encontros semanais dos grupos internos do MF - como voluntários, focolarinos casados e famílias novas - nos quais é comum empreendedores da EdC participarem de pelo menos um deles.

\section{Recursos comparados: formas de apoio ao empreendedorismo}

O Quadro 1 oferece um resumo dos recursos disponibilizados pelas duas organizações religiosas para seus membros, com ênfase nos aspectos ligados ao empreendedorismo e de acordo com as fases tradicionais do processo descritas na literatura desse campo de estudo (SHANE; VENKATARAMAN, 2000). Uma análise do quadro mostra que o MF possui uma maior diversidade de recursos organizacionais mobilizados para os empreendedores do que a IRC. Isso pode ser explicado por fatores como: maior tempo de vida da organização MF; o fato de terem criado um projeto específico de experiência econômica - a EdC, enquanto ideal, e os polos, enquanto projeto empresarial - que ajudou a sistematizar apoios que antes eram oferecidos juntamente com outros tipos de apoio religioso; e pelo fato de o MF ser de âmbito internacional, o que facilitou a importação de know-how já existente e de comprovada eficácia para a criação de recursos organizacionais (como os sites, o congresso nacional, o "Focolare", as comissões regionais e a organização da comunidade).

A IRC e o MF têm em comum a apropriação de suas organizações para outros fins que vão além dos objetivos originais, como o incentivo e apoio ao empreendedorismo. Essa característica da estrutura social, denominada "organização social apropriável" (COLEMAN, 1988), constitui um importante facilitador de capital social. Por exemplo, no caso da IRC, é a utilização do espaço da própria igreja para que um curso de finanças seja realizado ou para que se organize um seminário sobre a concepção de um plano de negócios, assim como para a promoção de networking entre os participantes. No MF, seus espaços também são utilizados para auxiliar outros propósitos além do exclusivamente religioso, por exemplo, a feira de exposições das empresas de EdC durante o congresso anual, a organização e desenvolvimento do polo empresarial e as reuniões do workshop da EdC. Em ambas as organizações, não há restrições importantes para que tais apropriações ocorram, e, pelo que se pode apreender, esse facilitador de capital social está mais desenvolvido no MF devido, principalmente, à existência de organizações desenvolvidas ao longo de mais de 30 anos - como as Mariápolis Permanentes e os Centros-Zona.

O fechamento de redes sociais (COLEMAN, 1988) é outro facilitador de capital social identificado na pesquisa. Os laços sociais estabelecidos nessas organizações são suficientes para que as sanções tenham efeito sobre a observância das normas, o que é bastante comum em organizações religiosas. Em decorrência disso, a confiança nas estruturas sociais é maior. Pode-se perceber, entretanto, que o MF possui esse facilitador de capital social mais proeminente do que a IRC, ou seja, a rede do MF é mais fechada. Atribui-se tal fechamento ao estilo mais comunitário de convivência do MF, o que acontece de maneira esparsa na IRC. Enquanto ser membro do MF é equivalente a participar de alguma atividade, pequenos grupos ou projetos como a EdC, 
ser membro da IRC pode significar tanto participar de um grupo de voluntariado voltado às ações beneficentes quanto ir apenas ao culto, o que dá um certo grau de anonimato aos membros e, portanto, faz com que as sanções coletivas em relação aos desvios da norma sejam aplicáveis de maneira limitada. Além disso, o sistema de comunicação interna do MF é mais eficiente e, devido a isso, há um sistema de reconhecimento dos membros (e não membros, como visitantes, simpatizantes etc.) também mais eficiente.

A IRC apoia seus empreendedores a partir de um ministério próprio, a Arepe, que é, ao mesmo tempo, uma associação empresarial de cunho civil. Como a Arepe é a responsável pela organização de qualquer evento relacionado ao empreendedorismo e mundo do trabalho, ela promove, além dos cultos voltados aos empresários, cursos, palestras técnicas e seminários que objetivam o desenvolvimento profissional e a construção de relacionamentos de seus adeptos. Os empreendedores também contam com o apoio emocional/ espiritual proporcionado pela estrutura da igreja, por meio de bispos e pastores que se dedicam ao ministério e que, entre outras atividades, auxiliam os empreendedores a tomar decisões na fase crítica entre a avaliação da oportunidade e a resolução de empreendê-la.

Além dos facilitadores de capital social citados acima, há formas de apoio direto ao empreendedorismo. Nesse sentido, uma das primeiras ações do MF foi a criação da Espri e do Polo Empresarial Spartaco, que abriga seis empresas de EdC e cujo modelo, construído ao longo do tempo, serve de referência na criação de outros polos no Brasil e no mundo. Essa iniciativa, embora ainda relativamente recente, apresenta claras indicações de se beneficiar das vantagens de aglomeração (do inglês, cluster ou agglomeration advantages), tais como facilidades no intercâmbio de informações, na obtenção de apoio financeiro e recursos de modo geral (incluindo, principalmente, recursos humanos), relações preferenciais de compra, melhor conhecimento das preferências dos consumidores, entre outras (TALLMAN et al., 2004). Dessas vantagens deriva, principalmente na fase de exploração da oportunidade, significativa redução nos custos de transação (MARTES; RODRIGUEZ, 2004b). Isso parece estar evidenciado nos relativamente baixos índices de encerramento de negócios entre as empresas associadas ao polo, tendo como importante indicador o fato de que apenas uma empresa encerrou suas atividades. Embora não tenha sido possível adquirir dados mais precisos sobre as exatas datas de fundação e encerramento desses negócios, uma simples comparação com o que poderíamos considerar uma taxa média de mortalidade empresarial após quatro anos de atividade - que, segundo diferentes autores, situa-se em torno dos 50\% (e.g., HEADD, 2003; de acordo com a pesquisa do Sebrae-SP de 2008, $50 \%$ das empresas paulistas encerram suas atividades

\section{Quadro 1 - Recursos disponibilizados pelas organizações religiosas para os empreendedores}

\begin{tabular}{|c|c|c|c|}
\hline DIMENSÕES & FASE & IRC & MF \\
\hline Formalização & & Arepe & EdC \\
\hline Informação & Identificação da oportunidade & $\begin{array}{l}\text { - Site da Arepe } \\
\text { - Balcão } \\
\text { - Quiosque da Arepe } \\
\text { - Programa de TV Ideias e negócios }\end{array}$ & $\begin{array}{l}\text { - Sites sobre a EdC } \\
\text { - Congresso nacional } \\
\text { - Rede dos "Focolares" } \\
\text { - Escritório da EdC } \\
\text { - Comissões regionais }\end{array}$ \\
\hline Formação & Avaliação da oportunidade & $\begin{array}{l}\text { - Palestras, seminários e cursos } \\
\text { - Culto Arepe }\end{array}$ & $\begin{array}{l}\text { - Congresso nacional } \\
\text { - Escolas de EdC } \\
\text { - Comissões regionais }\end{array}$ \\
\hline Motivação & Exploração da oportunidade & $\begin{array}{l}\text { - Conversas privadas, conselhos } \\
\text { - Culto Arepe } \\
\text { - Cultos e bênçãos nas empresas }\end{array}$ & $\begin{array}{l}\text { - Missa } \\
\text { - "Focolare" } \\
\text { - Comunidades organizadas (conversas } \\
\text { e conselhos) } \\
\text { - Polo Spartaco }\end{array}$ \\
\hline
\end{tabular}


nos primeiros quatro anos) - demonstra uma possível eficácia desse mecanismo de apoio à fase de exploração das oportunidades.

Uma segunda ação de apoio é a constituição das Comissões Regionais, que acompanham o desenvolvimento das empresas novas já constituídas; fornecem informações e consultoria; organizam palestras técnicas e intercâmbio de conhecimento entre as empresas; e oferecem apoio doutrinário sobre a EdC. A Associação Nacional por uma Economia de Comunhão, fundada em 2005, possui o papel de reunir e articular, em âmbito nacional, os envolvidos com o desenvolvimento da EdC. Há também o congresso nacional e as escolas de EdC, que servem como espaços de troca de informação e experiências empresariais, com enfoque em ações que têm por base a doutrina do MF. Isso indica que há uma rede articulada de amplitude nacional, importante fator de constituição de capital social e, igualmente, de grande potencial de apoio ao empreendedor na fase de exploração do empreendimento.

\section{CONCLUSÃO}

Empreendedorismo não se desenvolve apenas por motivos econômicos, mas também por valores introjetados e pelas formas de associação (WEBER, 2004). No caso das experiências aqui analisadas, a motivação religiosa-normativa, legitimada por um ideal secular de justiça social, é enfatizada entre os católicos pesquisados. Como decorrência, a principal preocupação desse grupo é refutar a tríade relacional entre economia-individualismo-egoísmo. No caso da experiência neopentecostal, a ênfase recai mais diretamente sobre as vantagens do pertencimento à Igreja e suas redes, sendo que os recursos organizacionais aparecem revestidos por um discurso que apela para um novo tipo de chamado, secular, mas sacralizado: o direito de ser rico e feliz, que Deus a todos concede, desde que abençoados na Terra pela igreja e não mais como predestinados, como no caso do calvinismo. Nesse sentido, ser rico e feliz adquire um caráter quase coercitivo de um dever para com Deus, o que acaba por legitimar o papel ativo da Igreja diante dos negócios.

A pesquisa mostra, igualmente, como formas específicas de capital social e de coesão comunitária - ou seja, de laços interpessoais mediados pela Igreja - são mecanismos fundamentais de apoio à atividade empresarial em suas várias fases. Tal dimensão é mais clara na Igreja Católica, onde inclusive parte dos negócios concentra-se numa mesma região, facilitando a conectividade, o adensamento das relações sociais e o maior fechamento da rede estabelecida em torno do Polo Spartaco.

Com base nos resultados desta pesquisa, observamos que dois pontos mencionados na Introdução - Igreja favorece formação de capital social e propicia motivação econômica - são reafirmados em ambas as organizações, mas com variação quanto à representação religiosa do significado do sucesso econômico e ao papel mais ativo dos católicos quanto à oferta de instrumentos de apoio específicos para as diversas fases do processo de empreendedorismo. Contudo, no caso do MF, esse papel mais ativo permanece restrito a um pequeno grupo, de modo que, quando se trata da igreja como um todo, o papel mais ativo/inclusivo é desempenhado pelos evangélicos.

Ambas as organizações conseguem promover relações de confiança no interior de suas redes, que constituem elemento essencial para manter a associação e desenvolver cooperação entre os participantes, elevando, assim, os níveis de capital social e fortalecendo os mecanismos de apoio ao empreendedorismo que oferecem. Parte desse capital foi constituída nas igrejas, antes mesmo do início de seu apoio aos negócios, especialmente no caso do MF, cujo fator "organização social apropriável" (COLEMAN, 1988) é decorrente da maior longevidade da organização, existente há décadas, tanto no Brasil quanto no exterior. Com a adesão aos projetos específicos, em ambas as organizações são colocados à disposição recursos organizacionais e simbólicos - como analisado nas dimensões espaços de informação, formação e motivação - que facilitam o desenvolvimento de atividades de identificação, avaliação e exploração de oportunidades, assim como criam um ambiente institucional de incentivo ao empreendedorismo.

O "fechamento de redes sociais" (COLEMAN, 1988) aparece como uma característica relevante da estrutura de relações capaz de incrementar o capital social. O MF é uma rede especificamente articulada no interior da Igreja Católica e sua proposta econômica projeta um ideal que requer, para fins de pertencimento, uma forte identidade ideológica: a economia de comunhão. Sua rede é mais fechada devido, principalmente, a essa ideologia e à valorização de um alto grau de convivência interna e sentido de coletividade. A IRC, por sua vez, oferece ajuda e cria recursos organizacionais com o propósito específico de promover o sucesso 
individual de seus empreendedores. As expectativas de compromisso partem da igreja em direção a cada um dos empresários, diferentemente do MF, onde os compromissos são estabelecidos entre os membros da rede dos "Focolares". Isso faz com que a rede da IRC seja mais difusa e descentralizada em relação à do MF, o que torna mais limitada a disponibilização de capital social.

Para futuras pesquisas, sugerimos o aprofundamento do tema capital social e sua especificidade em organizações religiosas, denominada por alguns pesquisadores "capital espiritual" (BERGER; HEGNER, 2003; WORTHAM; WORTHAM, 2007; SERAFIM; ANDION, 2010), bem como a investigação sobre a formação desse tipo de capital no Brasil e sua ligação com o empreendedorismo. Também entendemos que as três categorias de mecanismos encontradas empiricamente - espaços de informação, formação e motivação - são contribuições importantes ao tema pesquisado, principalmente pela sua evidente relação com as fases do empreendedorismo, podendo mesmo ser consideradas como uma tipologia da gama de serviços de apoio ao empreendedorismo oferecida pelas organizações a seus associados. Acreditamos que a continuação do exame dessa relação possa mostrar-se frutífera, não somente no âmbito de organizações do tipo das estudadas nessa pesquisa, mas também em organizações de outras naturezas ou ideologias. Finalmente, esperamos que este trabalho, pelo seu aspecto multidisciplinar, possa motivar pesquisadores a continuar investigando as influências institucionais na criação de capital social que reforça os mecanismos de suporte às várias etapas do processo de criação de negócios. Há grande interesse na identificação de políticas públicas e de mecanismos privados que, imersos em instituições de diferentes naturezas - inclusive religiosas -, tenham impacto positivo no estímulo ao empreendedorismo.

\section{REFERÊNCIAS}

ALDRICH, H. E. Entrepreneurship. In: SMELSER, N. J; SWEDBERG, R. (Eds). The handbook of economic sociology. 2nd ed. Princeton: Princeton University Press, 2005. p. 451-477.

BERGER, P. L; HEGNER, R. W. Spiritual capital in comparative perspective. 2003. Disponível em: http://tinyurl.com/ bergerke. Acesso em 10.9.2005.
BERGUOCI, L. Brasil é o maior país pentecostal. Folha de S. Paulo, 29.1.2007. Disponível em: http://www1.folha.uol. com.br/fsp/brasil/fc2901200708.htm. Acesso em 22.11.2010.

BOURDIEU, P. The forms of capital. In: RICHARDSON, J. (Ed). Handbook of theory and research for the sociology of education. New York: Greenwood Press, 1986. p. 214-258.

BRUNI, L. Comunhão e as novas palavras em economia. Vargem Grande Paulista: Cidade Nova, 2005.

BURT, S. R. A note on social capital and network content. Social Networks, v. 19, n. 4, p. 355-373, 1997.

BURT, S. R. The network structure of social capital. Research in Organizational Behaviour, v. 22, p. 345-423, 2000.

BURT, S. R. Structural holes versus network closure as social capital. In: LIN, N; COOK, K; BURT, S. R. (Eds). Social capital: theory and research. New York: Aldine de Gruyter, 2001.

BURT, S. R. Structural holes: the social structure of competition. In: DOBBIN, F. The new economic sociology: a reader. Princeton: Princeton University, 2004. p. 325-348.

BYGRAVE, W. D; HOFER, C. W. Theorizing about entrepreneurship. Entrepreneurship Theory and Practice, v. 16, n. 2, p. 13-22, 1991.

CASTILLA et al. Social networks in Silicon Valley. In: LEE, C. M; MILlER, W. F; ROWEN, H; HANCOCK, M. (Orgs). The Silicon Valley edge: a habitat for innovation and entrepreneurship. Stanford: Stanford University, 2000.

COLEMAN, .J. S. Social capital in the creation of human capital. The American Journal of Sociology, v. 94, p. S95-S120, 1988.

COLEMAN, .J. S. Foundation of social theory. Cambridge: Belknap, 1990.

DIMAGGIO, P. Aspectos culturais da acção e da organização econômica. In: PEIXOTO, J; MARQUES, R. A nova sociologia econômica: uma antologia. Oeiras: Celta, 2003. p. 167-194.

DURKHEIM, E. Da divisão social do trabalbo: as regras do método sociológico - as formas elementares da vida religiosa. São Paulo: Abril Cultural, 1978. (Os Pensadores) 
FELIN, T; ZENGER, T. R. Entrepreneurs as theorists: on the origins of collective beliefs and novel strategies. Strategic Entrepreneurship Journal, v. 3, p. 127-146, 2009.

GRANOVETTER, M. S. The strength of weak ties. The American Journal of Sociology, v. 78, n. 6, p. 1360-1380, 1973.

GRANOVETTER, M. S. Economic action and social structure: the problem of embeddedness. American Journal of Sociology, v. 91, n. 3, p. 481-510, 1985.

HEADD, B. Redefining business success: distinguishing between closure and failure. Small Business Economics, v. 21, n. 1, p. 51-61, 2003.

HUNG, S. C; HSIAO, Y. C. Mobilizing social capital to pursue entrepreneurship. In: International Engineering Management Conference (IEEE), p. 684-688, 2004.

IANNACCONE, L. R; KLICK, J. Spiritual capital: an introduction and literature review. 2003. Disponível em: http:// www.metanexus.net/spiritual_capital/research_review.asp. Acesso em 10.09.2005.

KOENIG, T; GOGEL, R. Interlocking corporate directorships as social networks. American Journal of Economics and Sociology, v. 40, n. 1, p. 37-50, 1981.

LIN, N. Building a network theory of social capital. Connections, v. 22, n. 1, p. 28-51, 1999.

LIN, N. Social capital. In: BECKERT, J.; ZAFIROVSKI, M. International Encyclopedia of Economic Sociology. London and New York: Routledge, 2006. p. 604-612.

LIGHT, I. Ethnic enterprise in America: business and welfare among Chinese, Japanese, and Blacks. Berkeley and Los Angeles: University of California, 1972.

LÓPEZ-RUIZ, O. J. O ethos dos executivos das transnacionais e o espírito do capitalismo. 2004. 375 p. Tese de Doutorado em Ciências Sociais, Instituto de Filosofia e Ciências Humanas da Universidade Estadual de Campinas, Campinas, 2004.

MARTES, A. C. B.; RODRIGUEZ, C. L. Church membership, social capital, and entrepreneurship in Brazilian communities in the U.S. In: Stiles, C. H; Galbraith, C. S. (Orgs). Ethnic entrepreneurship: structure and process. Boston: Elsevier Ltd., 2004a. v. 1, p. 171-202.
MARTES, A. C. B.; RODRIGUEZ, C. L. Afiliação religiosa e empreendedorismo étnico: o caso dos brasileiros nos Estados Unidos. RAC-Revista de Administração Contemporânea, v. 8, n. 3, p. 117-141, 2004b.

MARTES, A. C. B. New immigrants, new land: a study of Brazilian immigrants in Massachusetts. Gainesville: University of Florida, 2011.

MESQUITA, W. A. B. Correndo atrás da prosperidade: trabalho e empreendedorismo entre fiéis neopentecostais. Ciências Sociais e Religião, v. 9, n. 9, p. 195-215, 2007. Disponível em: http://goo.gl/gtQSj. Acesso em 20.02 .2011

MILlS, C. W. A nova classe média [White Collar]. Rio de Janeiro: Zahar, 1969.

OZGEN, E; BARON, R. A. Social sources of information in opportunity recognition: effects of mentors, industry networks, and professional forums. Journal of Business Venturing, v. 22, n. 2, p. 174-192, 2007.

PORTES, A. Social Capital: its origins and applications in modern sociology. Annual Review of Sociology, n. 24, p. 1-24, 1998.

PINHEIRO, M. B. Economia de comunhão: uma experiência peculiar de economia solidária. In: SINGER, P; SOUZA, A. R. de (Orgs). A economia solidária no Brasil: a autogestão como resposta ao desemprego. São Paulo: Contexto, 2000. p. 333-351.

PINTO, M. C. S; LEITÃO, S. P. Economia de comunhão: empresa para um capitalismo transformado. Rio de Janeiro: FGV, 2006.

PUTNAM, R. D. The prosperous community: social capital and public life. The American Prospect, v. 4, n. 13, 1993. Disponível em: http://prospect.org. Acesso em 05.03.2007

PUTNAM, R. D. Bowling alone: the collapse and revival of American community. New York: Simon \& Schuster, 2000.

QUARTANA, P. A economia de comunhão no pensamento de Chiara Lubich. In: QUARTANA, P. et al. Economia de comunhão. São Paulo: Cidade Nova, 1992. p. 11-22.

SERAFIM. M. C; ANDION, C. Capital espiritual e as relações econômicas: empreendedorismo em organizações 
religiosas. Cad. EBAPE.BR [on-line], v. 8, n. 3, p. 564579, 2010. Disponível em: http://goo.gl/aLsHK. Acesso em 05.03.2011

SHANE, S; VENKATARAMAN, S. The promise of entrepreneurship as a field of research. Academy of Management Review, v. 25, n. 1, p. 217-226, 2000.

SIEPIERSKI, C. T. Fé, marketing e espetáculo: a dimensão organizacional da Igreja Renascer em Cristo. Civitas, v. 3, n. 1, p. 127-146, 2003.

SIRMON, D. G; HITT, M. A; IRELAND, R. D. Managing firm resources in dynamic environments to create value: looking inside the black box. Academy of Management Review, v. 32, n. 1, p. 273-292, 2007.

SOUZA, A. R. Igreja in concert: padres cantores, mídia e marketing. São Paulo: Annablume; Fapesp, 2005.

STEINER, P. A nova sociologia econômica. São Paulo: Atlas, 2006.

SWEDBERG, R. Max Weber e a ideia de sociologia econômica. Rio de Janeiro: UFRJ; São Paulo: Beca Produções Culturais, 2005.

TALLMAN, S; JENKINS, M; HENRY, N; PINCH, S. Knowledge clusters and competitive advantage. Academy of Management Review, v. 29, n. 2, p. 258-271, 2004.

THORNTON, P. H. The sociology of entrepreneurship. Annual Review of Sociology, v. 25, p. 19-46, 1999.

WEBB, J. W; IRELAND, R. D; HITT, M. A; KISTRUCK, G. M; TIHANYI, L. Where is the opportunity without the customer? An integration of marketing activities, the entrepreneurship process, and institutional theory. Journal of the Academy of Marketing Sciences, v. 39, p. 537-554, 2011.

WEBER, M. A ética protestante e o "espírito" do capitalismo. São Paulo: Companhia das Letras, 2004.

WHYTE JR, W. H. The organization man. New York: Simon \& Schuster, 1956.

WORTHAM, R. A; WORTHAM, C. B. Spiritual capital and the "good life". Sociological Spectrum, v. 27, n. 4, p. 439452, 2007.
WUTHNOW, R. Religion and economic life. In: SMELSER, N. J; SWEDBERG, R. (Eds). The handbook of economic sociology. Princeton: Princeton University, 1994. p. 620-646.

WUTHNOW, R. New directions in the study of religion and economic life. In: SMELSER, N. J; SWEDBERG, R. (Eds). The handbook of economic sociology. 2nd ed. Princeton: Princeton University, 2005. p. 603-626. 